\title{
Influence of Vehicle Inspection Tests on Crashworthiness of School Bus in Nairobi County, Kenya
}

\author{
Bosire Thomas $\mathrm{M}^{1}$ and Dr Eng. Herbert Dimo ${ }^{2}$ \\ ${ }^{1} \mathrm{PhD}$ Student, Department of Technology Education, University of Eldoret, KENYA \\ ${ }^{2}$ Senior Lecturer, Department of Technology Education, University of Eldoret, KENYA \\ ${ }^{1}$ Corresponding Author: botmongare7@ yahoo.com
}

\begin{abstract}
The vehicle structure, designs and materials on school bus body crashworthiness as regulated by different government agencies in bus body building firms was the topic under research study. In Kenya, thousands of vehicles are involved in vehicle collisions or crashes every year resulting in fatal accidents and severe injuries to the passengers. The specific objective was the influence of vehicle inspection testson crashworthiness of school bus in Nairobi City County. This study adopted Dym's, Suh's Axiomatic theory. The pragmatic paradigm and explanatory research design were used. The target population was 1500 respondents from bus body building firms and government regulatory institutions. The sample size was 315 respondents. Questionnaires, interview schedules and observation were data collection instruments. Expert judgment was used to establish validity of the questionnaires. Cronbach's Alpha Coefficient was used to determine the reliability of the research instrument. The data collected was analyzed using descriptive and inferential analysis with the aid of SPSS V22 software. The coefficient of determination ( $R$ squared) of .206 showing that $20.6 \%$ of the variation in crashworthiness of a bus can be explained by vehicle inspection tests. There was a positive significant influence of vehicle inspection tests on crashworthiness of a bus $(\beta=0.396$ and $p<0.05)$. The study concluded that the vehicle inspection tests had a significant influence on the crashworthiness of school bus. The management of school bus body construction companies need to conduct all the terminal test needed before releasing the vehicle in order to enhance crashworthiness of a bus. The Transport authority should examine and check the mandatory requirements and periodically amend them in accordance with the safety, engineering and ecological standardization.
\end{abstract}

Keywords-- Vehicle, Inspection, Tests, Crashworthiness, Bus

\section{INTRODUCTION}

Crashworthiness is an engineering term used to define the ability of vehicle structure to protect its occupants during an impact [1]. In other words, crashworthiness is the process of improving the crash performance of a structure by sacrificing it under impact for the purpose of protecting occupants from injuries [1]. In
Canada in 2006, nearly two hundred thousand were injured in road accidents Transport Canada [2], bringing an estimate of $\$ 63$ billion in social costs. The majority of fatalities and serious injuries occurred due to frontal vehicle collisions [2].

In the U.S.A the Federal Motor Vehicle Safety Standard (FMVSS) No. 216, Roof Crush Resistance, established a minimum requirement for roof strength to "reduce deaths and injuries due to the crushing of the roof into the occupant compartment in rollover crashes". In this test, a rigid plate is pushed into one side of the roof at a constant speed. The roof must be strong enough to prevent the plate from moving 5 inches when pushed at a force equal to $1 \frac{1 / 2}{2}$ times the weight of the vehicle. The test went into effect in 1973 and remained essentially unchanged until an updated rule was announced in 2009, National Highway Traffic Safety Administration, [3]. Roof strength and injury risk in rollover crashes have a significant relationship[4].

Rollover accidents are recognized as the most dangerous accident scenarios for buses [5]. Even being a rare event, since only $4-5 \%$ of all bus accidents are rollovers, they are the cause of nearly $50 \%$ of serious and fatal injuries [6]\&[7]. The statistical data for cutaway buses accidents is not easily accessible. Not many countries keep track of bus accidents, especially cutaway buses. That is why many researchers use ordinary bus data to evaluate the seriousness of rollovers accidents in their research [8] \& [6]. One of the most useful tools for obtaining bus accident data for the United States is the Fatality Analysis Reporting System (FARS). FARS is a database providing yearly data regarding fatal injuries suffered in vehicle traffic crashes [9]. The most recent published FARS data, which is for the year 2012. In 2012 there were about 127 million cars registered in the United States, and they were involved in more than 18,000 fatal accidents.

According to this data, out of nearly 765,000 buses registered in the United States in the year 2012, there were only 249 fatal crashed involving buses. This results in about 140 lethal accidents per 1 million passenger vehicles registered, and more than 300 fatal accidents per one million buses. According to this data, there were only 11 rollover accidents out of all 251 fatal crashes involving 
buses (which makes it $4.4 \%$ of all bus crashes). Nearly $32 \%$ of all bus accidents with fatalities were associated with the bus rollover. Although, the selected FARS data does not specify the number of fatalities in each of the bus accidents, it shows general statistics and the ratio of vehicle to bus accidents which have occurred in the US during the year 2012 .

Research on buses and coach's safety is evidently limited. Some regulations compulsory for heavy vehicles are imposed for passenger protection. Federal Motor Vehicle Safety Standards (FMVSS) 220 establishes performance requirements for school bus rollover protection in the United States. In European community, United Nations Economic Commission for Europe (UNECE) Regulation-66 concerning with the strength of bus superstructure under dynamic lateral rollover test and ECE R80 specifying the strength of seats and their anchorages are enforced.

The regulations and/or guidelines specifically arranged for frontal collision of bus structure directly concerned with the safety of the driver and crew do not exist. However, the passengers are in much greater risk if the bus driver is not protected during the course of accident. Some proposals similar to ECE R29 are under discussions in Working Party on Passive Safety (GRSP) in UN-ECE and a similar regulation for buses will be imposed in the near future [10].

Road safety is a serious issue around the world, with more than 1.2 million people killed every year [11]. In the Province of Alberta in Canada alone, nearly 400 people are killed and more than 27,000 people are injured in over 112,000 motor vehicle collisions each year [2]. The direct social cost of motor vehicle collisions to Albertans is as much as $\$ 4.68$ billion, or $2.4 \%$ of Alberta's gross domestic product. Although school buses (SB) were involved in only $0.4 \%$ of the total number of collisions occurring in Alberta in the last decade, these crashes tend to receive disproportionate attention in the media and the community because of the high safety expectations for SB and the intensity of emotions involved when school children are injured. SB safety has a high priority in the community because parents put their trust in schools and SB drivers to transport their children to and from school safely.

About 6,000 SBs in Alberta, Canada, travel over 76 million kilometres each year to transport approximately 126,000 students in rural areas and 139,000 students in urban areas Opus Hamilton [12] and they are considered to be one of the safest modes. The proportion of SB collisions resulting in injury is $13.7 \%$, while the share of total collisions in Alberta that results in injury during the same time period is $15.2 \%$ [12]. Thus, there is a slightly lower risk of SB collisions resulting in injuries compared to all collisions.
In bus frontal collision, the driver safety is related to two opposite effects: deformation of driver compartment measured by intrusion; and deceleration felt by the driver measured by the amplitude and time duration of the crash pulse [13]. The use of components capable of buckling in a controlled progressive folding pattern is used as a mean to improve crashworthiness for vehicle occupant protection in passenger cars. Thin-walled steel tubes collapsing under axial crushing can also be as energy absorbers, most commonly exist as either square or circular cross sections [14], [15] \& [16].

In Kenya, there is growing concern by customers and stakeholders over the design of bus vehicles and the levels of crashworthiness based on past vehicle collisions or accidents. Bus vehicles involved in accidents according to experts, indicate that the design is substandard and moreover, the weight of the material is a great determinant of how safe a vehicle is, therefore rendering vehicle occupants or passengers more vulnerable to fatalities and serious injuries. According to experts, vehicles should be serviced before setting out on a long journey to ensure that they are roadworthy [17].

According to Wainaina [18] passenger service vehicles (PSV) will soon be required to adhere to new body construction standards before they are allowed to operate on the roads, according to the National Transport and Safety Authority (NTSA).The standard, referred to as KS372:2014, will be implemented to ensure the uniformity of all passenger vehicles and as a safety measure on the roads. "Bus accidents are fatal because of the poor construction of buses in Kenya," said Gerald Wangai, NTSA director of motor vehicle inspection.

According to NTSA, school buses involved in collisions based on previous experience, a school bus on impact or from impact, it is evident or clear that the body structure of the bus is weak and therefore not to the recommended manufacturing vehicle body standard. The problem under investigation is that in the event of a bus collision, why the bus structure or frame of the bus fails after an accident. This being a vehicle body safety aspect, it is very critical that it is studied and understood in order to set a safe and effective system which conforms to the design rules and standards. Therefore, there was need to determine the relationship between vehicle inspection testsand crashworthiness of school bus.

\section{LITERATURE}

\subsection{Crashworthiness of Bus}

An automobile can be impacted from any direction at different speeds. It can also include an automobile impacting another automobile, which in turn can be the same or different from the first automobile. This shows how automobiles affect and being affected by each other in crash 
situations [19]. An automobile can also impact a rigid barrier, a tree, a light post, and so on, which may lead to severe deceleration and high loads, as a rigid body cannot deform to absorb part of the impact energy. An automobile can also impact a pedestrian which leads to the importance of design for pedestrian safety as well, and finally an automobile can go into rollover accidents.

According to Galganski [20] crashworthiness problems can be characterized by: Displacement and energy: Frontal structure length is being reduced by modern design styles and at the same time, it is required to absorb most of the impact energy and to minimize intrusion into the compartment. Crash pulse: Crash pulse is the deceleration induced by impact on the human body. Head injury criterion (HIC) is used to measure the damage from crash pulse on the brain, and it should be less than a certain limit by regulations. Crash position: The structure should be able to mitigate injuries in different crash positions such as full-frontal impact, offset frontal impact, side impact, rear impact, and rollover. Automobile compatibility: With different automobile models, the structure should be able to mitigate injuries resulting from an accident involving two different automobiles, which can differ in size and/or weight.

Crashworthiness is not limited to automobiles only, it is also applied to other transportation vehicles, such as ships, planes, and trains. In fact, the first systematic and scientific investigation of the subject was applied to railway axles between 1879 to 1890 by Thomas Andrews [21]. Guler, Elitok, Bayram \& Stelzmann [22] looked into the effectiveness of a seatbelt usage on the rollover crashworthiness of the intercity coach. Authors attempted to evaluate passenger injury risk and compare the effectiveness of seatbelt usage during rollover accident. The authors used a Hybrid III 50th projectile dummy model obtained from LSTC to evaluate passenger injury in all investigated cases. Passenger restraints considered included passengers without seatbelts, 2-point lap belt and a 3-point shoulder belt. Use of the seatbelts during rollover test resulted in mitigation of projection and ejection of bus passengers and injury reduction.

Ko, Shin, Jeon \& Cho, [23] performed a study on the crashworthiness and rollover characteristics of the lowfloor bus made of sandwich composites. The composite incorporated into the vehicle structure was composed of the aluminum honeycomb and fiberglass-epoxy face sheets. The paper investigated two crash scenarios, a $60 \mathrm{~km} / \mathrm{h}$ frontal impact and the ECE-R66 rollover. Although material property tests were carried out on composite samples, no detailed validation effort was presented. Ozcanli and Yilmaz [24] investigated the effects of foam application to the bus structure in order to improve its crashworthiness during rollover accidents. Although the foam application to the structural beams reduced the deformation of the bus, the results were insignificant $(0.25 \%)$.

Iskandar and $\mathrm{Li}$ [25] looked at the aging effect, such as corrosion and deterioration of mechanical properties, on rollover crashworthiness of buses. Authors used data available on mechanical properties of corroded metals and applied these properties to the existing FE model of the bus. Conclusions show that aging effect has a significant influence onto the vehicle rollover crashworthiness and reduces bus occupant safety.

Computational and experimental experience, gained throughout this research, has shown that large variations exist in the crashworthiness of buses built by different manufacturers. These variations may be influenced by many structural characteristics such as: tubing selected for the steel cage (cross-sectional dimensions, thicknesses, open vs. closed cross-sections), connections between tubes including wall to floor and wall to roof joints, outer layer (thickness, material, connection to the cage), and others [8].

In terms of crashworthiness, structural deterioration of aged bus is the main concern during accident occurrence. Many factors contributed to the structural integrity degrade such as operation schedule, environment and loading effects and others. To improve the structure design for crashworthiness, it is required to understand the different factors affecting the crash process.

\subsection{Vehicle Inspection tests and Bus Crashworthiness}

According to American Public Transportation Association (APTA) Fact Book, after the introduction of ADA number of passenger trips on demand response services increased from 68 million in 1990 to 190 million in 2010 [26]. Out of all bus accident scenarios, rollover is considered to be the most dangerous one [27]. Clients often try to close this loophole by requesting compliance with an existing bus safety regulation. For the roof integrity evaluation of paratransit buses usually the Federal Motor Vehicle Safety Standard 220 (FMVSS 220) "School bus rollover protection" is adopted.

In the United States (US) as of 2005, the states that required paratransit manufacturers to comply with this existing standard included: Pennsylvania, Minnesota, Wisconsin, Tennessee, Michigan, Utah, Alabama, and California [28].

Alternative approach is presented in the Florida Standard for Crashworthiness and Safety Evaluation of Paratransit Buses (FDOT Standard) [29],[8]\& [30]. FDOT Standard, which was adopted by FDOT and became effective in 2007, is based on the United Nations Economic Commission for Europe Regulation 66 (ECE-R66) [31]. The ECE-R66 uses a full-scale dynamic rollover test as a basic approval procedure. The pass-fail criterion is based on a concept of a residual space (RS). The residual space is defined as a space required to be kept intact during a 
rollover in order to provide a survival zone for passengers and a driver.

In 2010, the State of Florida purchased over 300 of paratransit buses from seven different manufacturers. During that year the buses came with over 40 different floor/wheelbase/chassis configurations [32]. Such variety of purchased vehicles, gives the ordering agencies a flexibility of ordering vehicles optimized for desired purpose, but also creates a challenge for the approval procedure. Bus manufacturers are relatively small companies in comparison to the rest of automotive industry. They cannot afford of setting up and supporting their own R\&D departments or donating each manufactured model for rollover testing. On the other hand, the process of development, validation and verification of $\mathrm{FE}$ models for all purchased vehicles is an overwhelming task for a research institution such as Crashworthiness and Impact Analysis Laboratory (CIAL). It became apparent that the full-scale experimental rollover tests and the process of developing FE model for computer simulations are too expensive and time consuming to be effectively used in the current setting.

Paratransit bus accident statistics are not easily accessible. In the past, these types of buses were often lumped into general bus statistics, or "other buses" category. Until 2010, Fatality Analysis Reporting System (FARS), established by National Highway Traffic Safety Administration (NHTSA), did not contain a specific category for paratransit buses [3]. Starting from the Traffic Safety Facts 2011 report (NHTSA [33], a new special category named "Van-Based Bus (GVWR > 10,000 lb.)" was created to accommodate paratransit buses. So far, there is only two-year data $(2011,2012)$ available, and accounting a small number of this vehicles on the road, this is not sufficient to draw a full picture of fatal accidents for paratransit buses.

The CIREN database consists of multiple recorded severe vehicle crashes, including accident reconstruction and injury profile data. CIREN contains data extending back to 1996 and is available for public viewing [9]. NASS on the other hand, collects a nationally representative sample of police reported vehicle crashes of all types. Data is randomly sampled from available accident data and coded in detail according to NASS requirements [9]. Unfortunately, no cases for any bus accidents have been located in the CIREN database, and no data for bus rollover was found in NASS database. Due to the lack of the longterm accident statistics for paratransit buses, general bus accident statistics are more useful in drawing conclusions on injury mechanism of bus occupants. United Nations Economic Commission for Europe (UNECE) has been collecting data on bus accidents since 1973, when Hungary raised a problem of lack of requirements for the bus superstructure [27].
Other countries represented at the expert group IG/R.66 meeting in Madrid in January 2008, such as Czech Republic, United Kingdom, Italy, and Poland presented only fleet data, and did not provide bus accident statistics for their regions. Another study performed on Spanish bus data from 1995 to 1999 shows that the rollover accounted for $4 \%$ of all bus accidents, but the risk of fatalities was five times higher than for any other bus accident type [34]. Fatality Analysis Reporting System (FARS) is a useful tool for obtaining bus accident data for the United States. FARS is a nationwide database providing the public and decision makers with a yearly data regarding fatal injuries suffered in motor vehicle traffic crashes [9].

Spanish data collected in the 1990s lists injury distributions for bus accidents, comparing rollover accidents with all other types of crashes [34]. Based on this data, it has been found that a risk of a fatal injury is five times higher, and the risk of a serious injury is four times greater for rollover accident than for any other type of crash. Also, rollover accidents leave very few people uninjured as compared to all other types of crashes $(2.6 \%$ for rollover compared to $46.5 \%$ for other accidents). This data highlights the need to investigate the rollover accident scenario as the most dangerous for bus passengers. There is a need to investigate mechanism of injuries sustained by bus occupants during rollover in order to understand how the passengers could be protected. Unfortunately, FARS data doesn't provide injury details and cause of injury [35]. The best resources available in the US would be NASS and CIREN data from NHTSA, but neither one of these databases contains any bus rollover accidents. However, researchers from Europe have been collecting injury mechanism data for bus accidents, and since both accident populations show similarities, the European data is well applicable for the US market. A similar study performed in France presents a crucial data (1980-2005) for the injury mechanism of the occupants during bus accidents. The study, performed on 94 severe bus accidents consisted of $45 \%$ of frontal collisions, $42 \%$ of rollovers and $13 \%$ of other types of accidents [36].

Based on sensitivity analysis, authors selected critical structural variables for the optimization process. Bus weight, torsional stiffness, intrusion into residual space and stress values were used by the authors as a response function. The optimization process resulted with a $2.7 \%$ weight reduction, increase in torsional stiffness of $0.4 \%$ and a maximum stress reduction of $13.8 \%$. In a separate paper, Liang and Le [37] performed an optimization study on a bus superstructure strength, using the successive response surface method. The authors used LSDYNA as a FE solver and LS-OPT as an optimization software. Validation of the FE model was performed by comparing the roof, breast, and floor-pillar knots experimental and FE results. The optimization process resulted in the $40 \%$ and $50 \%$ of 
deformation reduction while increasing a bus weight by only $1.6 \%$.

Tech and Iturrioz [38] used a genetic algorithm to perform a structural optimization of a bus in rollover conditions. The authors constructed a simplified rigid beam FE model of a bus structure, and implemented addition plastic hinges in places where deformation was expected. Plastic hinges have been characterized by a series of experimental tests on bus components. Vehicle mass and mechanical response for the rollover experiment were chosen as the objective functions in this research. In a separate study, Bojanowski and Kulak [39] performed a multi objective optimization of the paratransit bus structure subjected to side impact and rollover tests. The objectives for the optimization included: mass of the cage structure, deformation in the rollover, intrusion distance in the side impact test. The authors concluded that the most important components of the bus structure responsible for $63 \%$ of variation in the objective functions were side wall and front cap structures.

The school bus manufacturer inspects all premanufactured parts to ensure that they are free from defects. The steel sheet metal is also inspected and then kept covered during storage to protect it from corrosion. After pieces of steel are cut from the sheet metal, they are inspected to be sure that they are the proper shape and size. When the chassis is complete it is driven briefly to ensure that the motorized components operate correctly. After the body is attached, the school bus is given a full road test to detect any flaws in operation. The school bus is sprayed with water to detect any leaks. The entire vehicle is given a detailed final inspection. All the items on a long, written list must be individually inspected and approved before the school bus is ready to be shipped. Safety is the major quality control concern for school bus manufacturers.

\section{THEORETICAL FRAMEWORK}

This study adopted a Dym's, Suh's Axiomatic theory. This theory Suh [40] describes design as a mapping between what designers want to achieve and how they achieve it. The framework of axiomatic design views design as a collection of mappings between four domains: the customer domain, the functional domain, the physical domain, and the process domain. In each domain the design is specified using different elements: customer attributes (CAs), functional requirements (FRs), design parameters (DPs), and process variables (PVs). In addition, there are constraints (Cs).

The design process starts with the identification of customer needs and attributes, and formulates them as FRs and constraints. These FRs are then mapped onto the physical domain by conceiving a design embodiment and identifying the DPs. There may be more than one solution to this mapping. Each DP is then mapped onto a set of PVs to define it. Each DP typically introduces new FRs, DPs, and PVs, and so the mapping process iterates by zigzagging between domains, until the design can be implemented without further composition. In principle this approach takes a broad view of design, but the axioms and methods are almost entirely about mapping from the functional to the physical domain, so they do not address all aspects of design. The principles of this theory potentially apply to a variety of design problems, including mechanisms, software, and organizations.

The methodology involves techniques for zigzagging between functional requirements and design parameters and the use of matrix algebra to assess independence. The theoretical framework has some appeal to experienced designers who recognize that achieving conflicting functional requirements with one design parameter (independence axiom violation) is the source of some badly compromised designs and that the information content embedded in the functional requirements might be a valid assessment of such complexity. Suh's axiomatic approach represents a substantial and potentially useful addition to design methods, but the technique has not shown significant practical application, as is discussed below. Moreover, the theoretical basis has some apparent limitations. It is not clear that Suh's assertion is correct that an ideal design always has an equal number of functional requirements and design parameters.

On the one hand, although we can agree that independence is desirable, design constraints such as manufacturability, low cost, and ease of use may at times conflict with independence or for objective reasons override independence. The best design, therefore, may have more functional requirements than design parameters. On the other hand, there are cases where decreased sensitivity to variations in use or manufacturing may be particularly important and can be improved by having more design parameters than functional requirements, Thus the independence axiom can result in a useful assessment tool but is not a requirement for all good designs. Further development of the information definition may also be needed to best meet customer needs rather than simply meeting the given tolerances.

In summary, the axioms while useful do not appear to constitute a complete and optimal design method. This could be why the best practical applications to date use axiomatic design in combination with other design methods. One can use the independence axiom in combination with robust Taguchi methods to examine which design parameters to use in achieving a robust design. One could also use axiomatic principles to assess concepts created by TRIZ methodology [41]. The axiomatic structure of this process does not guarantee the alternative with the highest rating will be the most preferred 
alternative. Unfortunately, it can be shown that the addition of a new alternative may change the ranking of existing alternatives, a property seen as undesirable in a decision process. The analytic hierarchy process has difficulty with uncertainty, which it can handle only in an approximate way. The process therefore provides no basis for valuing the elimination or reduction of uncertainty.

The main advantage of the analytic hierarchy process is ease of understanding and application. It may have real value in making decisions with robust influence factors, where there is no possibility of a major loss and where the complete set of alternatives is known a priori. The difficulty with the analytic hierarchy process, in addition to the theoretical features mentioned above, is that it cannot answer the questions necessary to build confidence in the selection of an alternative. The very simplicity of the process limits its ability to answer hard questions.

\section{RESEARCH METHODOLOGY}

This study adopted pragmatism as the philosophical underpinning of the research approach. Pragmatism is not committed to any one system of philosophy or reality. Pragmatist researchers focus on the 'what' and 'how' of the research problem [42]. While pragmatism is seen as the paradigm that provides the underlying philosophical framework for mixed-methods research Tashakkori \& Teddlie [43] some mixed-methods researchers align themselves philosophically with the transformative paradigm [44]. Mixed methods researchis an approach to inquiry that combines or associates both qualitative and quantitative forms. It involves philosophical assumptions, the use of qualitative and quantitative approaches, and the mixing of both approaches in a study.

This study adopted explanatory and descriptive research designs as it seeks to explain the phenomena under study by testing hypotheses and by measuring relationships between variables. According to Saunders, Lewis, \& Thornhill[45], studies that establish causal relationships between variables use explanatory design. The design is also deemed appropriate for the study as it allowed the study to be carried out in the natural settings and allow the researcher to employ probability samples. This was quantitative in nature and hypotheses tested by measuring the relationships between variables. The explanatory research design was suitable because the study was mainly be concerned with quantifying a relationship or comparing groups purposely to identify a cause-effect relationship.

The study area for the proposed research study was Nairobi City County. Nairobi is the principal industrial centre of the country. Nairobi is the East Africa's most populous city (3.5 million). Nairobi is a major business hub and many Aid agencies headquartered here as well. Nairobi has a modern city centre, some beautiful suburbs, as well as Africa's largest slum. The city is built on a plateau and it stays pleasantly cool year-round. Based on the foregoing facts about Nairobi city, the researcher found the location conducive for the research study since most of the organizations for the intended research are situated right in the city and county of Nairobi.

According to recent update by NTSA (National Transport and Safety Authority) in reference to vehicle road accident fatalities, Nairobi County remained the county with the most fatal crashes in 2015.Nairobi county contributed $22 \%$ of all the national fatalities in the year 2015.The update report also indicated/ noted that Nairobi County contributed the highest number of fatalities in the previous year, that is 2014 .

The target population was fifteen (15) registered bus vehicle body design companies with a total of 1500 employees comprising of technicians, supervisors and managers. Based on information from KABM (Kenya Association of Bus Manufacturers), it was established that there are almost twenty (20) bus vehicle body manufacturers operating in Kenya. Out of the twenty bus vehicle body manufacturers, only fifteen companies were legally registered to operate as at December, 2018.

Bus Vehicle Body Manufacturers in Kenya include Labh Singh and Harman Singh, Dodi Auto Tech, Banbros, CFG (Central Farmers Garage), Master Fabricators, KCI (Kenya Coach Industries), Truck World, Malva, Choda, Highlands, Kenya Vehicle Manufacturers, Toyota (Hino), CMC (Man, UD), Simba Colt (Fuso, Mitsubishi), and Isuzu. Representative from the following organizations were also considered namely: National Transport and Safety Authority (NTSA), Motor Vehicle Inspection Unit, Kenya Bureau of Standards (KEBS), National Police Service (National Traffic Police Headquarters) and Ministry of education staff (Public Schools) were also involved in this research study.

The study utilized purposive sampling to select fifteen (15) operations managers and 36 supervisors as they deal with the daily running of the school bus vehicle building in the bus construction firms. Simple random sampling was used to select 240 technicians to participate and was appropriate as it gave an equal chance of all respondent's inclusion in the sample. Using Yamane [46] sample size formula at $95 \%$ confidence level, $\mathrm{P}=0.05$. From the target population of 1500 employees, a sample size of 315 respondents was selected.

Research instruments aid a researcher in collecting information that is used in answering the research concerns in a study. A questionnaire contains a set of questions which can be answered by the research participants in a set of ways. A questionnaire was preferred in the study for collecting data because the questions, wordings and sequence are fixed and identical to all respondents. The 
questionnaire was in two parts: The first part covered background information of the respondents; the second part sought to answer the research questions. The questionnaires were administered to managers, supervisors and technicians within bus body building firms. An interview is a particular type of conversation between two or more people. Usually the interview is controlled by one person who asks questions. Basing on Kumar [47] the advantages of using a structured interview is that; the researcher was able to clarify any queries concerning the questions. A structured interview guide was used to gather information from NTSA, KEBS, MOE, Motor vehicle inspection unit and Kenya police traffic headquarters.

Before the actual data collection exercise took place, the researcher undertook a pilot study in Nakuru County among two bus body building firms. A sample of 20 respondents involving managers, supervisors and technicians. Piloting of the instruments was done using respondents from Nakuru town with similar characteristics with the study area. The purpose of the pilot study was to enable the researcher to ascertain the reliability and validity of the instruments, and to familiarize with the administration of the questionnaires.

The content validity of the instrument was determined by the study through discussion of the items in the instrument with the supervisors, lecturers from the department and colleagues. In order to evaluate the content validity of the instruments, the research came up with dimensions and elements that constituted adequate coverage as per the studies' objectives. As a check on face validity, research instruments were given to experts to obtain suggestions for modification. Advice given by these experts helped the researcher to determine the validity of the research instruments. The advice included suggestions, clarifications and other inputs.

Reliability of data collection tool is the ability to consistently yield the same results when repeated measurements are taken of the same individuals under the same conditions. In order to test the reliability of the instrument to be used in the study, the test- retest method was used; this entailed administering the same instruments to the same respondents twice after a give lapse of time.

Questionnaires were administered, collected data was analyzed using SPSS to determine the Cronbach's Coefficient Alpha. Cronbach's Coefficient Alpha was used to determine the reliability of the research instrument by correlating results from the two scores. A reliability coefficient of 0.7 was obtained. This showed that there was a strong relationship between the first and the second scores obtained after the instruments were administered.

After all data had been collected, the researcher conducted data cleaning, which involved identification of incomplete or inaccurate responses then correct them to improve the quality of the responses. The data was categorized, coded and entered in the computer for analysis using the Statistical Package for Social Sciences (SPSS V. 22). The data from questionnaires was analyzed using both descriptive and inferential statistical methods. Descriptive statistics consist of mean, and standard deviation, frequencies and percent. Inferential statistics consist of linear regression analysis. Data was presented by use of tables and graphs. Linear regression analysis was used to test the Hypotheses.

\section{RESULTS}

From the regression model, the coefficient of determination ( $\mathrm{R}$ squared) of .206 showing that $20.6 \%$ of the variation in crashworthiness of a bus can be explained by vehicle inspection tests. The adjusted R square of .202 depicts that vehicle inspection tests in exclusion of the constant variable explained the variation in crashworthiness of a bus by $20.2 \%$ the remaining percentage can be explained by other factors excluded from the model as summarized in table 1 . The standard error of estimate (.524) shows a small deviation of the independent variables from the line of best fit.

Table 1 Model Summary

\begin{tabular}{|c|c|c|c|c|}
\hline Model & $\mathrm{R}$ & $\begin{array}{c}\mathrm{R} \\
\text { Square }\end{array}$ & $\begin{array}{l}\text { Adjusted } \\
\text { R Square }\end{array}$ & $\begin{array}{l}\text { Std. Error of } \\
\text { the Estimate }\end{array}$ \\
\hline 1 & $.454^{\mathrm{a}}$ & .206 & .202 & .52440 \\
\hline
\end{tabular}

The regression model with vehicle inspection tests as a predictor was significant $(\mathrm{F}=58.295$, $\mathrm{p}$ value $=0.000)$ shows that there is a significant relationship between vehicle inspection tests and crashworthiness of a bus and at least the slope ( $\beta$ coefficient) is not zero as shown in Table 2. Therefore, this implies that there is a significant relationship between vehicle inspection tests and crashworthiness of a bus.

Table 2 ANOVA of Crashworthiness of a bus

\begin{tabular}{llllll}
\hline Model & $\begin{array}{l}\text { Sum of } \\
\text { Squares }\end{array}$ & df & $\begin{array}{l}\text { Mean } \\
\text { Square }\end{array}$ & F & Sig.
\end{tabular}

\begin{tabular}{llllll}
\hline $1 \begin{array}{l}\text { Regressio } \\
\mathrm{n}\end{array}$ & 16.031 & 1 & 16.031 & $\begin{array}{l}58.2 \\
95\end{array}$ & $.000^{\mathrm{b}}$ \\
& & & & & \\
Residual & 61.875 & 225 & .275 & & \\
Total & 77.906 & 226 & & & \\
\hline
\end{tabular}

a. Dependent Variable: Crashworthiness

b. Predictors: (Constant), Vehicle inspection tests

From regression analysis the $\beta$ coefficients for vehicle inspection tests were generated from the model, in 
order to test the hypotheses of the study. The $\beta$-value for vehicle inspection tests, had a positive coefficient, depicting positive relationship with crashworthiness of a bus. Table 3 gave the estimates of $\beta$-value and the contribution of the predictor to the model.

Table 3 Coefficients of Crashworthiness of a bus

\begin{tabular}{|c|c|c|c|c|c|c|}
\hline \multirow{2}{*}{\multicolumn{2}{|c|}{ Model }} & \multicolumn{2}{|c|}{$\begin{array}{l}\text { Unstandardi } \\
\text { zed } \\
\text { Coefficients }\end{array}$} & \multirow{2}{*}{$\begin{array}{c}\begin{array}{c}\text { Standardi } \\
\text { zed } \\
\text { Coefficie } \\
\text { nts }\end{array} \\
\text { Beta }\end{array}$} & \multirow[t]{2}{*}{$\mathrm{t}$} & \multirow[t]{2}{*}{$\begin{array}{l}\mathrm{Si} \\
\mathrm{g} .\end{array}$} \\
\hline & & B & $\begin{array}{l}\text { Std. } \\
\text { Error }\end{array}$ & & & \\
\hline & (Consta & 1.8 & .182 & & 9.8 & .0 \\
\hline & nt) & 05 & & & 97 & 00 \\
\hline 1 & Vehicle & .39 & .052 & .454 & 7.6 & .0 \\
\hline & $\begin{array}{l}\text { inspecti } \\
\text { on tests }\end{array}$ & 6 & & & 35 & 00 \\
\hline
\end{tabular}

a. Dependent Variable: Crashworthiness

Majority of the respondents agreed that all buses have $100 \%$ roll over compliant providing more stability to the structure. The company has experienced quality assurance team and company has under chassis inspection bay facility. The study findings depicted that there was a positive significant influence of terminal test and crashworthiness of a bus $(\boldsymbol{\beta}=0.396$ and $\mathrm{p}=0.000)$. An increase in terminal test led to an increase in crashworthiness of a bus. The null hypothesis (Ho) was rejected. Vehicle inspection tests had a significant influence on crashworthiness of a bus.

Vehicle inspection tests had a significant influence on crashworthiness of a bus. This concurs with Dant, [48] \&Sheller [49] that a purchase, customers enter a long-term relationship with their chosen product, the product manufacturer, and the dealer providing the after-purchase customer service.

Mugge, Schifferstein, \& Schoormans, [50] states that the contributors to attachment were found to be related to exceptional functionality of a product or memories built through product's lifecycle. To ensure consistent understanding of the evaluated attributes, clear descriptions containing the appropriate level of detail should be provided with the evaluation of various vehicle attributes.

The division of the customer journey into stages enables us to understand how the importance of various attributes changes over time and with experience of using the vehicle. This might have implications, for which attributes should be highlighted in marketing material and interactions at the dealership. It also gives an understanding of which attributes are most likely to drive brand loyalty in the longer term. The importance of these attributes may also differ between different groups of consumers and across different sectors of the car market.

\section{CONCLUSION}

The study concluded that the vehicle inspection tests had a significant influence on the crashworthiness of school bus. Absence of proper national standard/code of practice for bus body building design and approval to regulate and control the builders allowed the builder to follow their own experience. Thus, setting and implementing the rules for the body builders corrects the existing challenges and helps to manufacture quality products which are economical, safe and comfortable.

\section{RECOMMENDATION}

The Government of Kenya should through its multi-agency departments focus more on school outlined policy criteria. The Government of Kenya should develop a policy guideline to invoke a bus body recall in view of improved vehicle standards so as to conform to the changing bus vehicle body standards dynamics. The management of school bus companies need to conduct all the terminal test needed before releasing the vehicle in order to enhance crashworthiness of a school bus. The Transport authority should examine and check the mandatory requirements and periodically amend them in accordance with the safety, engineering and ecological standardization.

\section{REFERENCES}

[1] Jones, N. (2003). Several phenomena in structural impact and structural crashworthiness. European Journal of Mechanics-A/Solids, 22(5), 693-707.

[2] K Vodden, D Smith, F Eaton, \& DR Mayhew. (2007). Analysis and estimation of the social cost of motor vehicle collisions in Ontario. Canada: Transport Canada.

[3] Brumbelow, M. L., Teoh, E. R., Zuby, D. S., \& McCartt, A. T. (2009). Roof strength and injury risk in rollover crashesbus vehicle body construction standards requirements with a view to demand samples of materials used and final testing of a completed bus based on. Traffic Injury Prevention, 10(3), 252-265.

[4] Matolcsy, M. (2007). The severity of bus rollover accidents. Available at:

http://citeseerx.ist.psu.edu/viewdoc/download?doi=10.1.1.5 $15.2739 \&$ rep $=$ rep $1 \&$ type $=$ pdf.

[5] Gepner, B. D. (2014). Rollover procedures for crashworthiness assessment of paratransit bus structures. International Journal of Automotive Technology, 15(4), 581-591.

[6] Martínez-Ruiz, V., Lardelli-Claret, P., Jiménez-Mejías, E., Amezcua-Prieto, C., Jimenez-Moleon, J. J., \& Del Castillo, J. D. D. L. (2013). Risk factors for causing road 
crashes involving cyclists: An application of a quasiinduced exposure method. Accident Analysis \& Prevention, $51,228-237$.

[7] Bojanowski, C. (2010). Verification, validation and optimization of finite element model of bus structure for rollover test. Florida: Florida State University.

[8] National Highway Traffic Safety Administration. (2014). Crash Injury Research (CIREN). Available at: http://www.nhtsa.gov/CIREN.

[9] Cerit, M. E., Guler, M. A., Bayram, B., \& Yolum, U. (2010). Improvement of the energy absorption capacity of an intercity coach for frontal crash accidents. Available at: https://www.dynalook.com/conferences/international-conf2010/CrashSafety-3.pdf.

[10] WHO. (2004). World report on road traffic injury. Available at:

https://apps.who.int/iris/bitstream/handle/10665/42871/924

1562609.pdf;jsessionid=8153804E272BBAD10691092395 494A36? sequence $=1$.

[11] Opus Hamilton. (2008). Review of school bus collisions in Alberta. Available at: http://www.transportation.alberta.ca/Content/docType45/Pr oduction/reviewalbertaschoolbuscollisionsfinal.pdf.

[12] Matsumoto, A.T., Drimeier, L., \& Alves, M. (2012). Performance of polymeric reinforcements in vehicle structures submitted to frontal impact. International Journal of Crashworthiness, 17(5), 479-496.

[13] Abramowicz, W. (2003). Thin-walled structures as impact energy absorbers. Thin-Walled Structures, 41, 91107.

[14] Zhang, X. \& Zhang, H. (2012). Energy absorption limit of plates in thin-walled structures under compression. International Journal of Impact Engineering, 24, 121-131. [15] Nia, A.A. \& Parsapour, M. (2014). Comparative analysis of energy absorption capacity of simple and multicell thin-walled tubes with triangular, square, hexagonal and octagonal sections. Thin-Walled Structures, 74, 155165.

[16] Mwithimbu, K. (2014). Design of buses blamed for deaths, pp. 9-11.

[17] Wainaina, E. (2016). Boda boda riders protest woman rep's bus launch. Available at:

https://nairobinews.nation.co.ke/news/boda-boda-riders-

protest-woman-reps-bus-launch.

[18] Seiffert, U. \& Wech, L. (2007). Occupant protection. Automotive Safety Handbook, 2, 151-182.

[19] Galganski, R. A. (1993). Crashworthiness design of HSGGT vehicles. In Proceedings of the 1993 IEEE/ASME Joint Railroad Conference, pp. 121-130.

[20] McQuaid, J. \& Jones, N. (1999). A re-examination of Andrews' research on impact resistance of railway axles. International Journal of Impact Engineering, 22(7), 727738.
[21] Guler, M. A., Elitok, K., Bayram, B., \& Stelzmann, U. (2007). The influence of seat structure and passenger weight on the rollover crashworthiness of an intercity coach. International Journal of Crashworthiness, 12(6), 567-580.

[22] Ko, H. Y., Shin, K. B., Jeon, K. W., \& Cho, S. H. (2009). A study on the crashworthiness and rollover characteristics of low-floor bus made of sandwich composites. Journal of mechanical science and technology, 23(10), 2686-2693.

[23] Özcanli, M. \& Yilmaz, M. (2014). Effect of foam application in bus structure for conservation of residual space during rollovers. International Journal of Heavy Vehicle Systems, 21(1), 56-63.

[24] Iskandar, A. H., \& Li, Q. M. (2013). Ageing Effect on crashworthiness of bus rollover. Available at: https://www.dynalook.com/conferences/9th-european-lsdyna-conference/ageing-effect-on-crashworthiness-of-busrollover.

[25] Dickens, M., Neff, J., \& Grisby, D. (2012). Public transportation fact book. Washington, DC: American Public Transportation Association.

[26] Matolcsy, M. (2003). Lessons and conclusions-learned from the analysis of bus rollover accidents. In International Conference on Science and Motor Vehicles.

[27] Department of Transportation. (2005). Fatality analysis reporting system, 2005 data. Washington, DC: National Highway Traffic Safety Administration.

[28] Bojanowski, C., Kwasniewski, L., \& Wekezer, J. W. (2013). Comprehensive rollover testing of paratransit buses. International Journal of Heavy Vehicle Systems, 20(1), 7698.

[29] UNECE. (2006). Strength of the superstructure of large passenger vehicles. United Nations Economic Commission of Europe.

[30] Crashworthiness and Impact Analysis Laboratory (CIAL). (2011). Crashworthiness and Impact Analysis Laboratory (CIAL). Available at: https://www.eng.fsu.edu/ $\sim$ wekezer/research.html.

[31] National Highway Traffic Safety Administration. (2013). NHTSA announces final rule requiring seat belts on motorcoaches. Available at: http://www.nhtsa.gov/ About+NHTSA/Press+Releases/NHTSA+Announces+ Final+Rule+Requiring+Seat+Belts+on+Motorcoaches. [32] Martinez L, Aparicio F, Garcia A, Paez J, \& Ferichola G. (2003). Improving occupant safety in coach rollover. International Journal of Crashworthiness, 8(2), 121-132.

[33] National Transportation Safety Board. [NTSB]. (1999). Bus crashworthiness issues. Highway Special Investigation Report NTSB/SIR-99/04. Washington DC.

[34] UNECE. (2008). Report of the executive body on its twenty-fifth session held in geneva from 10-13 dec. 2007,

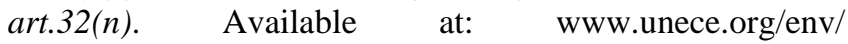
documents/2007/eb/ EB/ece.eb.air.91.e.pdf 
[35] Liang, C. C. \& Le, G. N. (2009). Bus rollover crashworthiness under European standard: an optimal analysis of superstructure strength using successive response surface method. International Journal of Crashworthiness, 14(6), 623-639.

[36] Tech, T. W. \& Iturrioz, I. (2009). Structural optimization of a bus in rollover conditions. Available at: https://www.sae.org/publications/technical-

papers/content/2009-36-0131/.

[37] Bojanowski, C. \& Kulak, R. F. (2011). Multi-objective optimisation and sensitivity analysis of a paratransit bus structure for rollover and side impact tests. International Journal of Crashworthiness, 16(6), 665-676.

[38] Suh, N.P. (1990). The principle of design. Oxford, England: Oxford University Press.

[39] Mann, D. (1999). Axiomatic design and TRIZ: Compatibilities and contradictions. The TRIZ Journal. Available at: http://www.triz-journal.com/.

[40] Creswell, J. W. (2009). Research design: Qualitative, Quantitative, and Mixed methods approaches. ( ${ }^{\text {rd }}$ ed.). University of Nebraska-Lincoln: SAGE Publications, Inc
[41] Tashakkori, A. \& Teddlie, C. (2010). Sage handbook of mixed methods in social \& behavioral research. UK: Sage Publications.

[42] Mertens, D. R. (2005). Rate and extent of digestion. Quantitative Aspects of Ruminant Digestion and Metabolism, 2, 13-47.

[43] Saunders, M., Lewis, P., \& Thornhill, A. (2011). Formulating the research design. Research Methods for Business Students, 130-161.

[44] Yamane, Taro. (1973). Statistics: An introductory analysis. New York: Harper \& Row.

[45] Kumar, V. (2012). 101 design methods: A structured approach for driving innovation in your organization. John Wiley \& Sons.

[46] Dant, T. (2004). The Driver-car. Available at: http://doi. org/10.1177/0263276404046061

[47] Sheller, M. (2004). Automotive emotions: Feeling the car. Theory, Culture \& Society. Available at: https://doi.org/10.1177/0263276404046068.

[48] Mugge, R., Schifferstein, H. N. J., \& Schoormans, J. P. L. (2010). Product attachment and satisfaction: understanding consumers' postpurchase behavior. Journal of Consumer Marketing, 27(3), 271-282. 